\title{
Study of Road Traffic Accidental (RTA) deaths in and around Jamnagar Region of Gujarat
}

\author{
Jitendra S Rathod ${ }^{1}$, Nikunj R. Pithadiya ${ }^{2}$, Kalpesh R. Chaudhari ${ }^{3}$, Hetalkumar kyada ${ }^{4 *}$ \\ ${ }^{1,3,4}$ Associate Professor, ${ }^{2}$ Tutor, ${ }^{1-4}$ Dept. of Forensic Medicine, ${ }^{1-3}$ M.P. Shah Medical College Jamnagar, ${ }^{4}$ PDU Government Medical \\ College,Rajkot, Gujarat, India.
}

*Corresponding Author: Hetalkumar C Kyada

Email: hardiksweet@yahoo.com

\begin{abstract}
Paediatrics is a branch of medicine which is concerned with wellbeing of infants, children, adolescents, their physical, mental, and psychological development. Paediatric forensic autopsy is useful to evaluate us the natural and unnatural childhood deaths, their reasons, steps for prevention and their management, which is both useful to the branch of Forensic Medicine and the Medical researchers. A 3 year retrospective study was conducted in M.P. Shah Government Medical College, Jamnagar during the period of January 2014 to December 2016. Out of total 3743 autopsies performed, a total of 253 cases belonging to paediatric age-group were the material of the study.

Accidental deaths are the most common manner of deaths and mostly affected age-group is 12-17 years. The leading cause of death are burns, drowning, road traffic accidents and snake bite. Accidental burns and suicidal hanging were more common in females in the agegroup 12-17 years. Accidental drowning and RTA were common in the males. In the present study, snake bite envenomation was also one of the leading causes of unnatural deaths in children and was mostly seen in the age range of 2-10 years. In India, both natural and unnatural childhood deaths are emerging as major public health problem. Various educational programmes, preventive strategies, and dissemination of information are necessary to create awareness and is must to reduce the unnatural deaths.
\end{abstract}

Keywords: Paediatric autopsy, Unnatural children deaths, Trauma, Manner of death.

\section{Introduction}

WHO defined accident as an unexpected, unplanned occurrence that may involve injury. ${ }^{1}$ Accidents represent a major epidemic of non-communicable disease in the present century world over. They are a part of the price we pay for technological progress. The death rate is highest and still growing in lower and middle-income countries, where pedestrians, motorcyclists, cyclists and passengers are especially vulnerable.

A steep increase in vehicle and human population traversing the adverse road situations has made road traffic injuries a serious condition. ${ }^{2}$ Road accidents are human tragedy. They involve high human suffering and monetary costs in terms of ultimately deaths, injuries and loss of potential income. During the calendar year 2010, there were close to 5 lac road accidents in India, which resulted in more than 1.3 lac deaths and inflicted injuries on 5.2 lac persons. These numbers translate into one road accident death every 4 minutes. Unfortunately, more than half the victims are economically active age group of 25-65 years. The loss of the main bread winner can be catastrophic. ${ }^{3}$

\section{Materials and Method}

The present study was carried at the Department of Forensic Medicine M. P. Shah Government Medical College, Jamnagar during the period of June 2016 to June 2017. Retrospective study of total 155 cases of road traffic accidental death cases autopsied was studied.

A detailed data was taken as to the circumstances of death with special reference to any history suggestive of road traffic accident. Data like age, sex, mode of transportation, body part involved in injury, survival period, and cause of death was recorded from police papers, relative's history, hospital treatment papers \& post mortem report.

\section{Results}

Out of the 155 cases studied $128(82.58 \%)$ were males and 28(17.42) were females. Maximum 39(25.16\%) cases were in $3^{\text {rd }}$ decade followed by $29(18.70 \%)$ in after $6^{\text {th }}$ decade. Maximum male cases recorded $35(22.58 \%)$ in $3^{\text {rd }}$ decade. Maximum female cases $7(4.51 \%)$ in after $6^{\text {th }}$ decade. In the $1^{\text {st }}$ decade, no any female death was recorded.

The Body region involved in maximum 141(90.96\%) cases was head \& neck followed by lower limb $112(72.25 \%)$ cases, then upper limb involved in $106(68.38 \%$ ) cases, thorax was involved in 90(58.06\%) cases, abdomen and pelvis were involved in lowest $59(38.06 \%)$ cases.

Head injury was the most common cause of death with maximum 90(58.06\%) cases, followed by multiple injuries with $56(36.12 \%)$ cases while spinal injury as a cause of death was recorded in only $1(0.64 \%)$ case.

Out of 155 cases studied, two wheeler users were maximum involved in RTA with $105(67.74 \%)$ cases followed by pedestrians involved in 29(18.70\%) cases, while minimum $6(3.87 \%)$ cases recorded in heavy motor vehicle users.

Maximum 135(87.09\%) cases had survival period of 0 - 1 day followed by $11(7.09 \%)$ cases which had survival period of 1 day -1 week. Only 3 cases were having survival period of more than 1 month.

Subdural haemorrhage was present in maximum $118(76.12 \%)$ cases. While combined intracranial haemorrhages were present in 104(67.09\%) cases. Extradural haemorrhage was present in minimum $32(20.64 \%)$ cases. 
Maximum involved long bone was rib with 43(27.74\%) cases, while fracture of tibia \& fibula was second most common with $20(12.90 \%)$ cases. Radius and ulna were least involved with $11(7.09 \%)$ cases.

In the present study, brain was the most common involved visceral part. Among pedestrians, brain was involved in 23 cases followed by lungs, kidneys \& intestines with 4 cases each. Heart was involved in only 1 case. Among two wheeler users, brain was involved in 91 cases following by lungs with 8 and then liver in 7 cases. Among three wheeler transportation, brain was involved in maximum 8 cases, followed by lungs and intestine with 1 case of each. Among four wheeler users, brain was involved in maximum 7 numbers of cases while lungs involved in only 1 case. Among heavy motor vehicle users, brain was involved in maximum 6 numbers of cases while lungs, liver, $\&$ spleen involved in 1 case.

Parietal bone is involved in maximum $45(29.03 \%)$ cases following by frontal bone involved in $42(27.09 \%)$ cases. Occipital bone is minimum involved in 26(16.77\%) cases.

The maximum cases were recorded in July with 19(12.25\%) cases followed by November 16(10.32\%), and February and April with $15(9.67 \%)$ each. In January lowest $8(5.16 \%)$ cases were recorded.
Table 1: Age \& Sex wise distribution

\begin{tabular}{|c|c|c|c|c|c|c|}
\hline Age(years) & Total & \% & Male & \% & Female & \% \\
\hline $0-10$ & 3 & 1.93 & 3 & 1.93 & 0 & 0 \\
\hline $11-20$ & 19 & 12.25 & 17 & 10.96 & 2 & 1.29 \\
\hline $21-30$ & 39 & 25.16 & 35 & 22.58 & 4 & 2.58 \\
\hline $31-40$ & 28 & 18.06 & 23 & 14.83 & 5 & 3.23 \\
\hline $41-50$ & 16 & 10.32 & 12 & 7.74 & 4 & 2.58 \\
\hline $51-60$ & 21 & 13.54 & 15 & 9.67 & 5 & 3.87 \\
\hline$>60$ & 29 & 18.70 & 22 & 14.19 & 7 & 4.51 \\
\hline
\end{tabular}

Table 2: Involved body region wise distribution

\begin{tabular}{|c|l|c|c|}
\hline Sr. No. & Body region & No. of cases & \% \\
\hline 1 & Head \& Neck & 141 & 90.96 \\
\hline 2 & Thorax & 90 & 58.06 \\
\hline 3 & Upper limb & 106 & 68.38 \\
\hline 4 & Abdomen \& & 59 & 38.06 \\
\hline 5 & Lower limb & 112 & 72.25 \\
\hline
\end{tabular}

Table 3: Mode of transportation wise distribution

\begin{tabular}{|c|l|c|c|}
\hline Sr. No. & Mode of transportation & Number & $\%$ \\
\hline 1 & Pedestrian & 29 & 18.70 \\
\hline 2 & Two wheeler & 105 & 67.74 \\
\hline 3 & Three wheeler & 9 & 5.80 \\
\hline 4 & Four wheeler & 8 & 5.16 \\
\hline 5 & Heavy motor vehicle & 6 & 3.87 \\
\hline
\end{tabular}

Table 4: Involved viscera parts according to mode of transportation

\begin{tabular}{|c|c|c|c|c|c|c|}
\hline Sr. No. & $\begin{array}{c}\text { Visceral } \\
\text { parts }\end{array}$ & $\begin{array}{c}\text { Pedestrian } \\
(\mathbf{2 9})\end{array}$ & $\begin{array}{c}\text { Two wheeler } \\
(\mathbf{1 0 5})\end{array}$ & $\begin{array}{c}\text { Three } \\
\text { wheeler } \\
\mathbf{( 9 )}\end{array}$ & $\begin{array}{c}\text { Four } \\
\text { wheeler } \\
\mathbf{( 8 )}\end{array}$ & $\begin{array}{c}\text { Heavy motor } \\
\text { vehicle(6) }\end{array}$ \\
\hline 1 & Brain & $23(79.31 \%)$ & $91(86.66 \%)$ & $8(88.88 \%)$ & $7(87.5 \%)$ & $6(100 \%)$ \\
\hline 2 & Lungs & $4(13.79 \%)$ & $8(7.61 \%)$ & $1(11.11 \%)$ & $1(12.5 \%)$ & $1(16.66 \%)$ \\
\hline 3 & Heart & $1(3.44 \%)$ & - & - & - & - \\
\hline 4 & Liver & $3(10.34 \%)$ & $7(6.66 \%)$ & - & - & $1(16.66 \%)$ \\
\hline 5 & Spleen & $3(10.34 \%)$ & $4(3.80 \%)$ & - & - & $1(16.66 \%)$ \\
\hline 6 & Kidneys & $4(13.79 \%)$ & $4(3.80 \%)$ & - & - & - \\
\hline 7 & Others & $4(13.79 \%)$ & $3(2.85 \%)$ & $1(11.11 \%)$ & - & - \\
\hline
\end{tabular}

Table 5: Cause of death wise distribution

\begin{tabular}{|c|c|c|c|}
\hline Sr. No. & Cause of death & No. of cases & $\%$ \\
\hline 1 & Head injury & 90 & 58.06 \\
\hline 2 & Thoracic injury & 3 & 1.93 \\
\hline 3 & $\begin{array}{c}\text { Abdominal } \\
\text { injury }\end{array}$ & 5 & 3.22 \\
\hline 4 & $\begin{array}{c}\text { Multiple } \\
\text { injuries }\end{array}$ & 56 & 36.12 \\
\hline 5 & Spinal injury & 1 & 0.64 \\
\hline 6 & Lower limb & 2 & 1.29 \\
\hline
\end{tabular}

\section{Discussion}

This study is to evaluate incidence and prevalence of road traffic accidental deaths. Following are the discussion points with other studies on the various parameter of observation:
Age

As per our study out of the total 155 cases studied $128(82.58 \%)$ were males and $28(17.42)$ were females. Maximum $39(25.16 \%)$ cases were in $3^{\text {rd }}$ decade $(21-30$ year) followed by $29(18.70 \%)$ in $6^{\text {th }}$ decade. Maximum male cases were recorded $35(22.58 \%)$ in $3^{\text {rd }}$ decade. Maximum female cases $7(4.51 \%)$ in after $6^{\text {th }}$ decade. In the $1^{\text {st }}$ decade none female death was recorded. Young drivers and riders are in more risk of crash accidents. Young often tend to be overconfident, less experienced, run with high speed and use of alcohol makes the worse combination of risks. Unnecessary travel and joy ride and choice of less safe travel modes are a habit with adolescents. ${ }^{4}$ More than half of the road traffic casualties are in the wage earning age group. The loss of the main earning member can be disastrous, leading to fall in income of the household and lower living standards. $^{3}$ The study conducted at Pondicherry ${ }^{5}$ showed that below and above the age of 20 and 49 years, there was 
less accident. The reasons may be that children are taken care of by elders and less use of vehicles in the adolescent age group. Lower proportion of RTAs in those aged 60 and above could be due to the generally less mobility of the people. In a hospital based study by Ganveer $\mathrm{G} B$ et al. ${ }^{6}$ majorities of the victims were in the age group 18 to 37 years and $17.97 \%$ cases were aged more than 37 years. The study by Gururaj ${ }^{7}$ found that mortality rate among different age groups was $8.2 \%$ (<14 years), 62\% (15-44 years), $20 \%$ (45-59 years) and $9.2 \%$ ( $>60$ years). The study by Ghimire et al. ${ }^{8}$ showed that injury was common in the age group of 40-49 years $(4.6 \%)$. A study from Tanzania ${ }^{9}$ concludes that the transport related injuries to be much common among adults, 15 years and above. Agarwal et al. ${ }^{10}$ in study, showed that the fifty nine percent of RTA victims were in age group of 20 to 40 years with mean age was 36.5 years with a range from 3 years to 60 years. A study from Bhopal in a tertiary hospital by Khare et al, ${ }^{11}$ shows that the highest number of victims $634(50 \%)$ were from 16 - 30 years of age group. It was followed by $31-45$ years age group. Age wise mortality among RTA cases was higher in 16-30 years $12(30 \%)$ age group followed by $31-45$ years $(27.5 \%)$. A study conducted by Dandona et al. ${ }^{12}$ had shown that majority of the persons killed in RTA were aged between 16 and 49 years of age, followed by 16 and 29 years of age. The people of the most active and productive age group are involved in RTAs, which adds a serious economic loss to the community. Similar observations were also made by others. $^{13,14}$

\section{Sex}

As per our study out of the 155 cases studied $128(82.58 \%$ ) were males and $28(17.42 \%)$ were females. A study from Delhi $^{15}$ found that the males are much more exposed to RTAs than females. However, in another study, male and Female ratio was very high (9:1). The study conducted by Sathiyasekaran et al, ${ }^{16}$ and Varghese et al, ${ }^{17}$ found that $80 \%$ of the victims involved in RTAs were males. According to a study by Jha et al, ${ }^{5} 83 \%$ of the accident victims were males. Seventy three per cent of total deaths occurred among men, with a ratio of $3: 1$ between men and women. Ganveer $\mathrm{G} \mathrm{B}$ et $\mathrm{al}^{6}$ in a study had shown that the male: female ratio of $6: 1$ can be attributed to the fact that proportion of males as compared to females is more and in our society as males are the bread earners for the family and therefore involved usually in outdoor activities exposing themselves to accidents. Moshiro C et al (2005) ${ }^{9}$ have found that males had significantly increased risk of transport injuries as compared to females. A study by Agarwal et al, 10 showed that eighty four percent of RTA victims were males. Khare $\mathrm{N}$ et al, ${ }^{11}$ at a tertiary care hospital, had shown that out of 1268 RTA cases $1047(82.5 \%)$ of the victims were males \& rest 221(17.5\%) were females.

\section{Mode of transportation}

In our study out of 155 cases studied two wheeler users are maximum involved in RTA with 105(67.74\%) cases followed by pedestrians involved in 29(18.70\%) cases, while minimum $6(3.87 \%)$ cases recorded in heavy motor vehicle users. Among three wheeler users 9(5.80\%) cases recorded among them most of the victims are passengers. Among four wheeler users $8(5.16 \%)$ cases recorded. Pedestrians \& vehicular occupants were equally involved in some study. In some studies, pedestrians were more involved than vehicular occupants. ${ }^{18,} 19$ This shows the erratic pedestrian behavior and reckless driving of vehicles on the roads. Majority of the occupants belonged to two wheelers in our study, which is consistent with other studies. ${ }^{18,19}$ The increasing trend of driving two-wheelers by college students, who have tendency to drive fast, is probably the reason for increased two-wheeler accidents.

\section{Survival period}

In our study, out of 155 cases studied majority cases $135(87.09 \%)$ cases have survival period less than 1 day or spot death. While 11 cases have survival period of 1 day to 1 week, and 8 cases have survival period of 1 week to 1 month and only 3 cases have survival period more than 1 month among them death occurred due to complications of injuries occurred during road traffic accidents. As per study of C.behera ${ }^{20} 65.96 \%$ cases have survival period less than 1 day while only $6.38 \%$ cases have survival period 1 day to 1 week. This shows the severity of road traffic accidents.

\section{Body region involved}

In our study out of 155 cases, body region involved in maximum $141(90.96 \%)$ cases is head \& neck following by lower limb 112(72.25\%) cases, then upper limb involved in $106(68.38 \%$ ) cases, thorax is involved in $90(58.06 \%)$ cases, abdomen and pelvis are involved in lowest $59(38.06 \%)$ cases. This suggests that head and neck is more prone to be injured during road traffic accident and survival chances are reduced due to this. Similar results are found as per study of C.behera, ${ }^{20}$ Head and face was the most vulnerable body region involved in $89.36 \%$ of cases followed by extremities $(55.32 \%)$ In a study by Sirathranont J \& Kasantikul V, ${ }^{21}$ upper and lower extremities were injured most frequently, although these injuries were not life threatening. The most fatal injuries to the motorcyclists were to the head, abdomen, and chest in decreasing frequency. In a similar study by Doyle D et $\mathrm{al}^{22}$ legs, arms, head and thorax were the most commonly injured body regions. Serious injury to one or both of the latter two regions appeared to be implicated in the fatal outcomes.

\section{Cause of death}

In our study out of 155 cases studied head injury is most common cause of death with maximum $90(58.06 \%)$ cases, following by multiple injuries with $56(36.12 \%)$ cases while spinal injury as a cause of death recorded in minimum $1(0.64 \%)$ case, While abdominal injury as a cause of death is present in $5(3.22 \%)$ cases. Thoracic injury as a cause of death present in $3(1.93 \%)$ cases. While $2(1.29 \%)$ cases recorded of lower limb injuries. Salgado 23(69.6\%), Biswas $\mathrm{G}^{18}(47.3 \%)$ and present study $(58.06 \%)$ shows head injury as a major cause of death. Head injury as a cause of death 
can be explained by the fact that most of cranio-cerebral injuries were not the result of primary impact but due to secondary impact or secondary injuries or both.

\section{Type of intracranial haemorrhage}

In our study out of 155 cases studied subdural haemorrhage is present in maximum $118(76.12 \%)$ cases. While combined intracranial haemorrhages present in 104(67.09\%) cases. Extradural haemorrhage is present in minimum $32(20.64 \%)$ cases, while $84(54.19 \%)$ cases of subarachnoid haemorrhages are present. In the present study, the most common type of intracranial haemorrhage found was subdural haemorrhage $(77 \%)$, which is consistent with the study of Akang et $\mathrm{al}^{24}(62.4 \%)$. This is followed by subarachnoid haemorrhage, which was found in $55 \%$ cases of our study and $24.6 \%$ in Akang et $\mathrm{al}^{24}$ study. Whereas, study done by Chandra et $\mathrm{al}^{25}$ showed subarachnoid haemorrhage as most common type $(66.9 \%)$, followed by subdural haemorrhage $(58.2 \%)$. Extradural, intracerebral and intraventricular haemorrhages were found in significantly less number of our cases, which is in concurrence with other studies. $^{24,25}$

\section{Fractured long bones}

In the present study, maximum involved long bone is rib with $43(27.74 \%)$ cases, while fracture of tibia \& fibula is second common with $20(12.90 \%)$ cases. Radius and ulna are least involved with $11(7.09 \%)$ cases and femur bone is involved in $18(11.61 \%)$ cases.

\section{Involved skull bone}

In our study, parietal bone is involved in maximum $45(29.03 \%)$ cases following by frontal bone involved in $42(27.09 \%)$ cases. Occipital bone is minimum involved in $26(16.77 \%)$ cases, while temporal bone is involved in $35(22.58 \%)$ cases, and base of skull involved in $29(18.70 \%)$ cases. Skull fractures were found in $62 \%$ of our cases, which involved vault and base equally. In the studies done by Chandra et $\mathrm{al}^{25}$ and Akang et al ${ }^{24}$ skull fractures were found in $79.87 \%$ and $38.2 \%$ respectively. This shows that fatalities are more common in head injuries associated with skull fractures than those without fractures. As per study of Dr. Anand Menon \& Dr. Nagesh K. R ${ }^{26}$ external injury to the face \& scalp were found in $82 \%$ of the victims. In $62 \%$ of cases, fracture of skull was found. Fissured fracture was the most commonly observed fracture (57\%). Whereas, comminuted fracture, diastatic fracture and depressed fracture were seen in $18 \%, 16 \%$ and $9 \%$ respectively. Cranial vault was involved in $38 \%$, base of skull in $34 \%$ and both vault and base in $28 \%$ of cases. The sites of skull fractures are shown in table3. Middle cranial fossa, parietal bone and temporal bone were the commonly involved areas in fracture, which corresponds to $26 \%, 22 \%$ and $20 \%$ respectively. Least involved area in fracture is occipital bone.

\section{Visceral parts involved}

Out of total 155 cases studied, brain is most common involved visceral part. Among pedestrians, brain is involved in 23 cases following by lungs, kidneys \& intestines with 4 cases each. Heart is involved in only 1 case. Among two wheeler users brain is involved in 91 cases followed by lungs with 8 and then liver in 7 cases. Among three wheeler transportation, brain is involved in maximum 8 cases followed by lungs and intestine with 1 case of each. Among four wheeler users brain is involved in maximum 7 numbers of cases while lungs involved in 1 case. Among heavy motor vehicle users, brain is involved in maximum 6 numbers of cases while lungs, liver, \& spleen involved in 1 case. Visceral injuries in different categories of victims were similar with study done by Salgado ${ }^{23}$ All visceral injuries showed consistency with the skeletal injuries observed in different categories of victims as the possible explanation of the production of injuries given before. In cases of pedestrians and occupants of the vehicle, in spite of fewer incidences of external injuries, incidence of brain injury was higher and proved fatal in present study.

\section{Month of the year}

In our study, maximum cases were recorded in July with $19(12.25 \%)$ cases. Followed by November $16(10.32 \%)$, and February and April with 15(9.67\%) each. In January lowest $8(5.16 \%)$ cases were recorded. July and November month have festival season so more people are involved in road traffic accident. Mehtha S P et al ${ }^{27}$ and Ghosh P K et $\mathrm{al}^{15}$ in their studies had shown that the highest no. of accident victims were in January compared to other calendar months. There was some increase in number of RTAs in the month of October, which may be attributed to the rainy season.

\section{Conclusion}

Maximum numbers of males are involved in road traffic accidents and maximum deaths are recorded in $3^{\text {rd }}$ decade (21-30) years. Head is the main body region involved and head injury is cause of death with presence of subdural haemorrhage in maximum number of road traffic accidents. Maximum two wheeler users are involved in road traffic accidental deaths with highest number in July month and the survival period is only of one day.

\section{Recommendations}

1. Plan road networks such that, different types of traffic are channeled along different roads specifically designed for each type.

2. Provide safe crossings and separate paths for pedestrians and cyclists.

3. Improve the visibility of roads, road signs during both day and night.

4. Enforce strict laws that set maximum blood alcohol content levels for drivers.

5. Control speed with traffic calming road design such as roundabouts and enforce speed limits consistently with speed breakers. 
6. Follow the traffic signal and signal boards without fail especially at vulnerable areas like accident zones, school areas.

7. Avoid usage of mobile telephones while driving.

8. General health check-up at least twice a year for drivers.

9. Helmets should be made compulsory for all riders of bicycles, motorcycles and the mopeds.

10. Timely and adequate treatment for RTA cases at hospitals.

\section{Source of funding: None.}

\section{Conflict of interest: None.}

\section{References}

1. WHO 2003; 81(9):684-5.

2. Mohan D. Road traffic injuries-a neglected pandemic. Bulletin World Health Guru raj G, Kolluri SVR, Chandramouli BA, Subbakrishna DK, Kraus JF. Traumatic Brain Injury. National Institute of Mental Health \& Neuro Sciences 2005; Publication no. 61 .

3. Government of India ministry of road transport and highways transport research wing. New Delhi: Road accidents in India; 2012.

4. Sunder Lal, Adarsh, Pankaj. Textbook of Community Medicine. ${ }^{\text {rd }}$ edition. CBS Publishers \& Distributors pvt Ltd, New Delhi: 2008:588.

5. Nilambar Jha. Epidemiological study of road traffic accident cases: a study from south India. Indian J Community Med 2004;29(1).

6. Ganveer G B, Tiwary R. Injury pattern among non fatal road traffic accident cases; a cross sectional study in Central India. Indian J Med Sci 2005;59(1):9-12.

7. Guru raj G. Injuries in India: A national perspective Department of Epidemiology WHO Collaborating Centre for Injury Prevention and Safety.

8. Ghimire A, Nagesh S, Jha N, Niraula SR, Devkota S. An epidemiological study of injury among urban population, Kathmandu Univ Med J 2009.

9. Moshiro C, Heuch I, Astrom AN, Setel P, Hemed Y, Kvale G. Injury morbidity in an urban and rural area in Tanzania: an epidemiological survey. BMC Public Health 2005;5:11.

10. Agarwal A. Sociodemographic profile of road traffic accident victims admitted at emergency surgical OPD of a tertiary care hospital. J Postgrad Med, Education Res 2012;46(1):15-18.

11. Khare N, Gupta SK, Varshney A, Athavale AV. Epidemiological Study of Road Traffic Accident Cases Attending Tertiary Care Hospital, in Bhopal Madhya Pradesh. Natl J Community Med 2012;3(3):395-9.

12. Dandona R, Mishra A. Death due to road traffic crashes in Hyderabad city in India: Need for strengthening surveillance. Natl Med J India 2004;17:74-9.

13. Chunli C, Huichun W, Xiaohong S. The investigation and analysis of 1000 cases of traffic injury emergency treatment in five cities in China 1991. Proceedings of International Conference of Traffic Safety, New Delhi, India 1991:27-30.

14. Balogun JA, Abreoje OK. Pattern of road traffic accident cases in a Nigerian University Teaching Hospital.

15. Ghosh PK. Epidemiological study of the victims of vehicular accidents in Delhi. J Indian Med Assoc 1992;90(12):309-12.

16. Sathiyasekaran BWC. Study of the injured and the injury pattern in road traffic accident. Indian J Forensic Sci 1991;5:63-8.
17. Varghese, Mohan D. Transportation injuries in rural Haryana, North India 1991. Proceedings of International Conference on Traffic Safety, New Delhi, India 1991:27-30.

18. Biswas G, Verma SK, Sharma JJ, Aggarwal NK. Pattern of Road Traffic Accidents in North East Delhi. J Forensic Med Toxicol 2003;20(1):27-32.

19. Patel SN. Traffic Fatalities in Lusaka, Zambia. Med Sci Law 1979;19(1):61-5.

20. C.behera, ravi rautji, sanjeev lalwani \& T. D. Dogra, a comprehensive study of motorcycle fatalities. J Indian Acad Forensic Med, 31(1).

21. Sirathranont $\mathbf{J}$ and Kasantikul V. Mortality and injury from motorcycle collisions in Phetchaburi Province. J Med Assoc Tha. 2003;86(2):97-102.

22. Doyle D, Muir M and Chinn B. Motorcycle accidents in Strathclyde Region, Scotland during 1992: A study of the injuries sustained. Health Bull (Edinb). 1995;53(6):386-94.

23. Salgado MSL, Colombage SM. Analysis of fatalities in road accidents. Forensic Sci Int 1998;36:91-6

24. Akang EEU, Kuti MAO, Osunkoya AO. Pattern of fatal head injuries in Ibadan - A 10 year review. Med Sci Law 2002;42(2):160-6.

25. Chandra J, Dogra TD, Dikshit PC. Pattern of Craniointracranial injuries in fatal vehicular accidents in Delhi 196676. Med Sci Law 1979;19(3):186-194.

26. Dr. anand menon \&dr. nagesh K. R, pattern of fatal head injuries due to vehicular accidents in manipal, JIAFM 2005:27(1).

27. Mehta SP. An epidemiological study of road traffic accident cases admitted in Safdarjung Hospital, New Delhi. Indian J Med Res 1968;56(4):456-66.

How to cite this article: Rathod JS, Pithadiya NR, Chaudhari KR, kyada H. Retrospective study of pediatric autopsy findings in a tertiary care center: an evaluation. Indian $J$ Forensic Community Med 2019;6(4):250-4. 